\title{
Fuzzy controlled SVC for power system damping
}

\author{
Zalina Kamis, Mohd Ruddin Ab. Ghani, Muhammad Nizam Kamarudin, Hairol Nizam Mohd Shah \\ Center for Robotics and Industrial Automation, Faculty of Electrical Engineering, Universiti Teknikal Malaysia Melaka, \\ Malaysia
}

\begin{tabular}{l}
\hline \hline Article Info \\
\hline Article history: \\
Received Apr 23, 2019 \\
Revised Jul 30, 2019 \\
Accepted Sep 25, 2019 \\
\hline
\end{tabular}

\section{Keywords:}

Fuzzy logic controller (FLC)

Damping control

Power system stabilizer (PSS)

Static var compensator (SVC)

\begin{abstract}
This paper presents the ability of the fuzzy logic-based stabilizer used to generate the supplementary voltage control signal of the SVC to improve the damping of the inter-area mode oscillation in the power system. The base system is symmetrical, consisting of two identical areas connected by a relatively weak tie line. The SVC is chosen to be installed at the tie line midpoint. The active power of the local line will be used as an input signal for the stabilizer. The additional signal is calculated using fuzzy membership function to determine the quantity of reactive power supplied absorbed by SVC. The system oscillation is indicated by a 3-phase-to-ground short circuit occurring at $0.2 \mathrm{~s}$ of the simulation and subsequently clearing after $100 \mathrm{~ms}$. Simulation with the sample power system shows that when subjected to a disturbance, fuzzy logic-based SVC stabilizer provides good damping in inter-area mode oscillation for the system. The effectiveness of the stabilizer applied with and without PSS will also be investigated.
\end{abstract}

\section{Corresponding Author:}

Zalina Kamis,

Center for Robotics and Industrial Automation,

Faculty of Electrical Engineering,

Universiti Teknikal Malaysia Melaka, Malaysia

Email: zalina_fz@yahoo.com.sg

\section{INTRODUCTION}

Stability of the power system is the system's ability to regain its original operating conditions after a system disturbance. Transient stability analysis of the power system is considered with large disturbances such as sudden changes in the load, generation or transmission system configuration due to fault or switching [1]. Dynamic voltage support and reactive power compensation were identified as a very significant measure for improving the transient stability of the system. Flexible AC Transmission Systems (FACTS) devices with an appropriate control strategy have the potential to increase the system stability margin [2-6]. Shunt FACTS devices play an important role in th e power network's reactive power flow.

Low-frequency electro-mechanical oscillations often follow electrical disturbances in large power systems. Generally, Power System Stabilizers (PSS) are used in conjunction with Automatic Voltage Regulators (AVR) to dampen the oscillations [3]. However, this device may not produce adequate damping during certain operating conditions, and other effective alterations are needed in addition to PSS [7,8]. Another ways of achieving damping is to use the same shunt FACTS device Static Var Compensator (SVC) designed with auxiliary controllers [9-13]. SVC is therefore more effective and, if accommodated with an additional controller, by adjusting the equivalent shunt capacity, SVC will dampen the oscillations and improve the overall stability of the system [14].

Recently, a great deal of effort has been directed towards the application of fuzzy control in power systems [14-18], as well as a few papers with application of fuzzy control to SVC [19-21]. A significant contribution to system damping can be made when a SVC is controlled over its voltage control loop by some auxiliary signals [22-26]. A FLC can be designed taking into account the non-linearity of the power system. 
A fuzzy-based SVC stabilizer used to generate the additional SVC voltage control loop signal is proposed in this paper. Using Fuzzy membership, the additional signal is calculated. Fuzzy logic control approach is an emerging tool to solve complex problems with complex system behavior in nature. An attractive feature of Fuzzy Logic Control is its robustness in system parameters and changes in operating conditions [27]. Fuzzy logic controllers are able to tolerate greater uncertainty and imprecision [22].

\section{MODELLING AND CONTROL OF SVC}

The Static Var Compensator is basically a shunt-connected Var generator whose output is adjusted to exchange the system's capacitive or inductive current. One of the SVC's most widely used configurations is the FC-TCR type in which a Fixed Capacitor (FC) is connected in parallel with the Thyristor Controlled Reactor (TCR). The magnitude of the SVC is the inductive admittance BL $(\alpha)$ which is a function of the firing angle $\alpha$ and is given by.

$$
\begin{aligned}
& X_{S}=\frac{V_{S}^{2}}{Q_{L}} \\
& B_{L}(\alpha)=\frac{2 \pi-2 \alpha+\sin 2 \alpha}{\pi X_{S}}
\end{aligned}
$$

for $\pi / 2 \leq \alpha \leq \pi$ where

$\mathrm{V}_{\mathrm{S}}=\mathrm{SVC}$ bus bar voltage and $\mathrm{Q}_{\mathrm{L}}=\mathrm{MVA}$ rating of reactor. As the SVC uses a fixed capacitor and variable reactor combination (TCR- FC), the effective shunt admittance is.

$$
B_{S}=\frac{1}{X_{C}}-B_{L}(\alpha)
$$

where $\mathrm{X}_{\mathrm{C}}=$ Capacitive reactance.

For simplicity, a SVC with a firing control system can be represented by a first order model characterized by a KSVC gain and time constants $\mathrm{T} 1$ and T2 as shown in Figure 1. The controller sends firing control signals to the thyristor switching unit to modify the SVC's equivalent capacitance. The fuzzy controller provides an auxiliary control that is in addition to the voltage feedback loop. The SVC's auxiliary control loop uses stabilizing signals such as speed, frequency, phase angle difference, etc. to improve system dynamic performance.

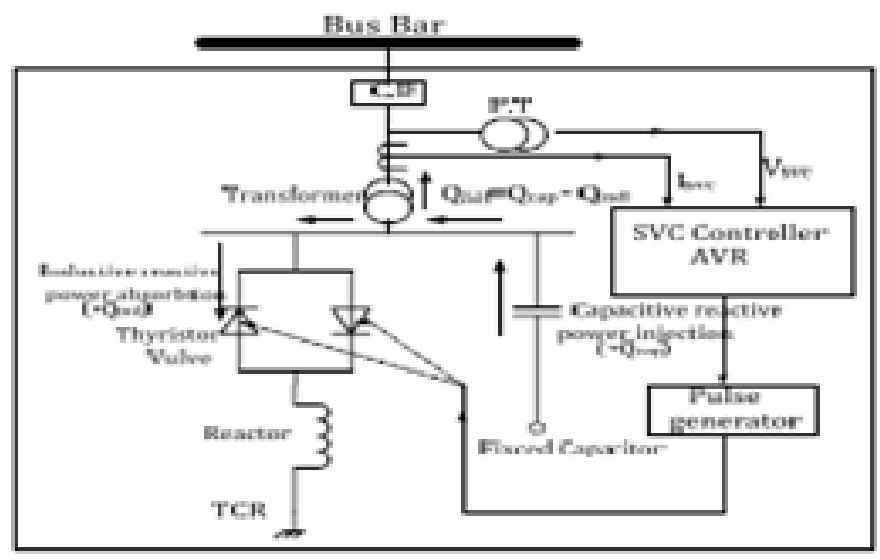

Figure 1. SVC based control system

\section{REVIEW OF FUZZY LOGIC}

Fuzzy logic is a basic control system that relies on the degrees of state of the input and the output depends on the state of that state's input and rate of change. In other words, a fuzzy logic system works on the principle of assigning a specific output depending on the probability of the input state. Fuzzy logic works on the concept based on assumptions to decide the output. It works on sets basis. Each set represents some 
linguistic variable defining the possible output state. Every possible state of the input and the degrees of change of the state are part of the set, depending on which output is predicted. It basically works on the If-else-the principle, i.e. if AND B Then Z.

Suppose we want to control a system where the output can be anywhere in the set $\mathrm{X}$, with a generic value $\mathrm{x}$, so that $\mathrm{x}$ belongs to $\mathrm{X}$. Consider a specific set $\mathrm{A}$ which is a subset of $\mathrm{X}$, so that all members of $\mathrm{A}$ belong to the interval 0 and 1 . The set $A$ is known as a fuzzy set, and the value of $f A(x)$ at $x$ denotes the membership degree of $\mathrm{x}$ in that set. The output is decided based on the $\mathrm{x}$ membership degree in the set. This membership assignment depends on the assumption of outputs depending on the inputs and input change rate.

These fuzzy sets are graphically represented using membership functions and the output is determined based on the degree of membership in each part of the function. The IF-Else logic decides the membership of the sets. Generally speaking, the set variables are the state of the inputs and the degrees of input changes, and the membership of the output depends on the logic of AND operation of the input state and the input change rate. The variables can also be the different inputs for a multi-input system, and the output can be the possible result of the AND operation between the variables.

A Fuzzifier that transforms the measured or input variables into linguistic variables in numerical forms. A controller that performs the fuzzy logic operation of assigning outputs based on linguistic information. To achieve the control logic, it performs approximate reasoning based on human way of interpretation. The controller consists of the base of knowledge and the inference engine. The knowledge base consists of membership functions and fuzzy rules, which are obtained by environmental knowledge of system operation. The defuzzifier converts this fuzzy output to the system control output required.

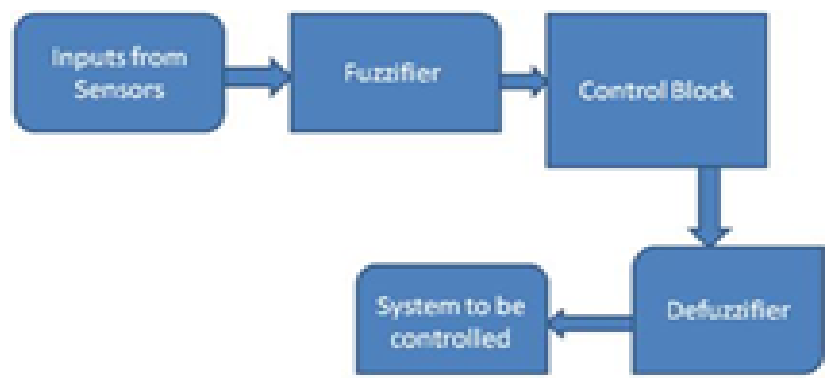

Figure 2. A fuzzy logic control system

\section{FLC BASED DAMPING CONTROLLER DESIGN}

Figure 3 shows the fuzzy logic controlled SVC for improved damping. The generator speed deviation $(\Delta \omega)$ and $(\Delta \mathrm{P})$ are taken as the fuzzy controller input signals.

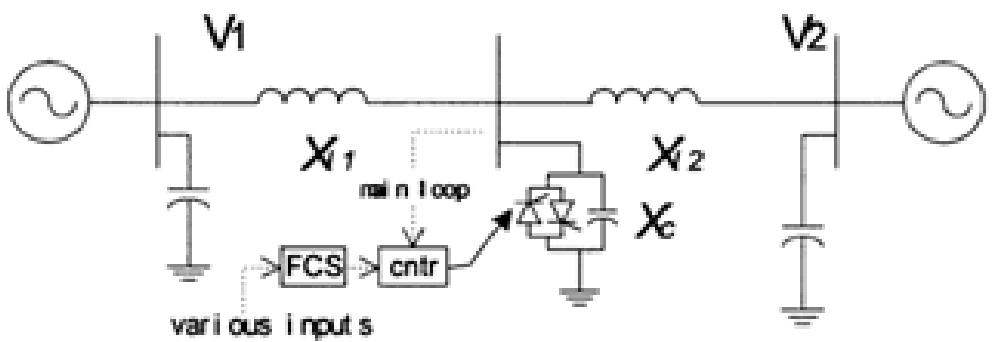

Figure 3. Fuzzy logic controlled SVC setup

For each variable, the number of membership functions determines the quality of control that can be achieved using fuzzy logic controllers. Five membership functions for the input and output variables are defined in the present investigation. Figure 4 shows defined membership functions. The aforementioned membership functions are used to specify a set of rules called the rule base. The developed rules are based on 
knowledge and experience. With two inputs and five linguistic terms, 25 rules have been developed which are set out in Table 1. In the inference mechanism, all the rules are compared with the inputs to determine which rules apply to the current situation. The required rules will be fired after the matching process. The controlled Bsvc output is determined for the different input conditions. The defuzzification produces FLC's final crisp output with the fuzzified input. Centroid method is used where the output is calculated as.

$$
O / P=\frac{\sum_{i=1}^{5} b_{i} \int \mu_{(i)}}{\sum_{i=1}^{5} \int \mu_{(i)}}
$$

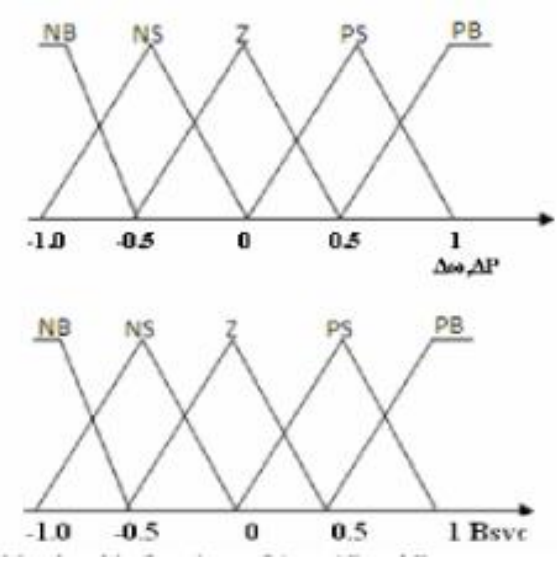

Figure 4. Membership functions of $\Delta \omega, \Delta \mathrm{p}$ and $\mathrm{B}_{\mathrm{SVC}}$

Table 1. Fuzzy inference rules

\begin{tabular}{cllllll}
\hline Output (BSVC) & & & & $\Delta \mathrm{p}$ & \\
\hline \multirow{4}{*}{$\Delta \omega$} & & NB & NS & Z & PS & PB \\
& NB & NB & NS & NB & NS & Z \\
& NS & NS & NB & Z & Z & PS \\
& Z & NS & Z & Z & PS & PS \\
& PS & Z & Z & PS & PS & PS \\
& PB & Z & PS & PS & PS & PB \\
\hline
\end{tabular}

\section{SIMULATION RESULTS}

Simulation studies are carried out in two machine three bus transmission line power systems for the most severe fault conditions to assess the effectiveness of the proposed controller. Simulation details are presented here. This example described in this section illustrates the modeling of a simple transmission system that contains 2-hydraulic power plants. SVC has been used to improve transient stability and oscillation damping of the power system. The method of phasor simulation can be used. Figure 5 shows a single line diagram representing a simple $500 \mathrm{kV}$ transmission system.

500 kV Transmission System

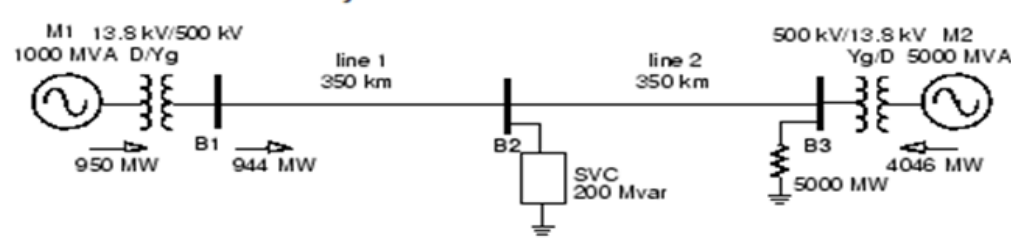

Figure 5. Single line diagram of 2 machine power 
A $1000 \mathrm{mw}$ hydraulic generation plant $(\mathrm{m} 1)$ is connected to a load center through a $500 \mathrm{kv}$ long transmission line totaling $700 \mathrm{~km}$. A resistive load of $5000 \mathrm{mw}$ is modeled as the load center. The load is fed by the remote 1000 mva plant and a local 5000 mva generation (plant m2). On this system a load flow was performed with plant $\mathrm{m} 1$ generating $950 \mathrm{mw}$ so that plant $\mathrm{m} 2$ produces $4046 \mathrm{mw}$. The line carries $944 \mathrm{mw}$ which is close to its surge impedance loading $(\mathrm{sil}=977 \mathrm{mw}$ ). In order to maintain system stability after faults, a 200 mvar static var compensator (svc) compensates the transmission line at its center.

The svc has no controller unit. Machine \& svc parameters were taken from ref [10]. In order to maintain system stability after faults, a 200 mvar static var compensator (svc) compensates the transmission line at its center. Any disturbances caused by fault in power systems can result in the induction of electromechanical oscillations of electrical generators. Such oscillating swings need to be effectively damped to maintain system stability and reduce the risk of breaking out of synchronism

Simulations are performed for a system shown in Figure 6 for severe three-phase fault conditions to assess the efficacy of the fuzzy controller and results are compared for a PI controller and a fuzzy controller. Figure 7-8 shows the graphs of relative rotor angles and speed graphs with PI controller and fuzzy controller. From the graphs it is observed that damping is poor with conventional PI and the damping effect has been significantly increased with the auxiliary fuzzy controller. It was observed that the proposed fuzzy controller has better robustness than a well-designed conventional PI controller. The simulations are shown Figure 6-8.

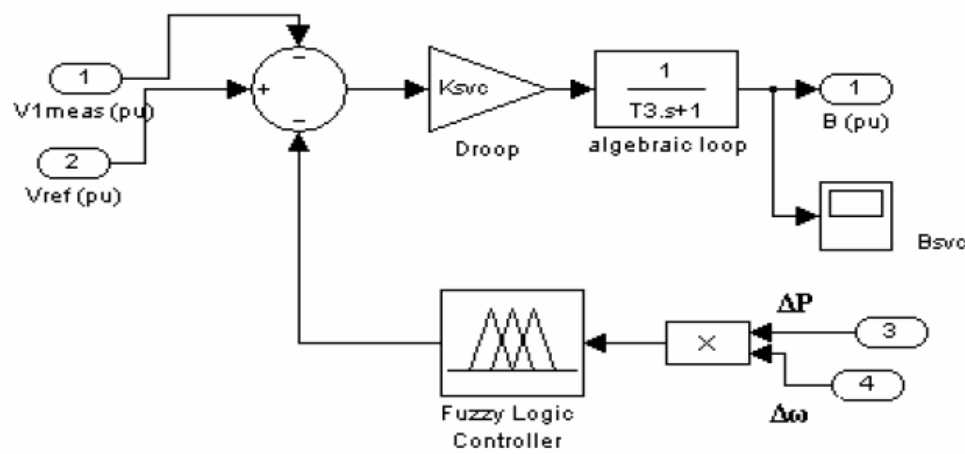

Figure 6. SIMULINK model of FLC controller for SVC

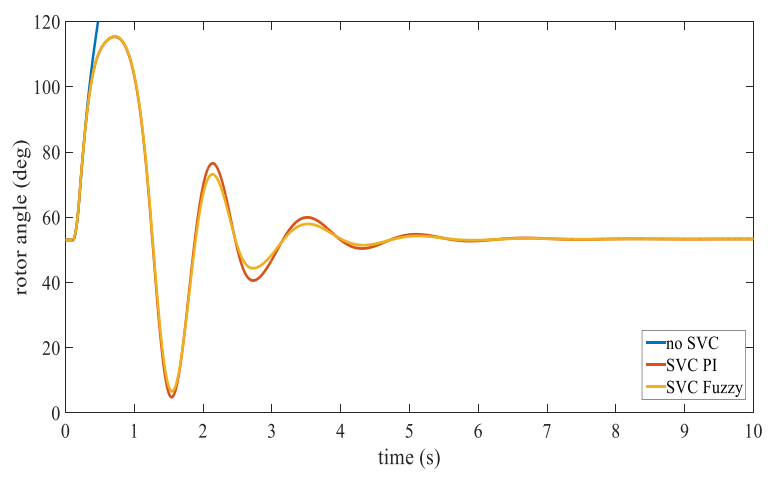

Figure 7. Rotor angle different (deg)

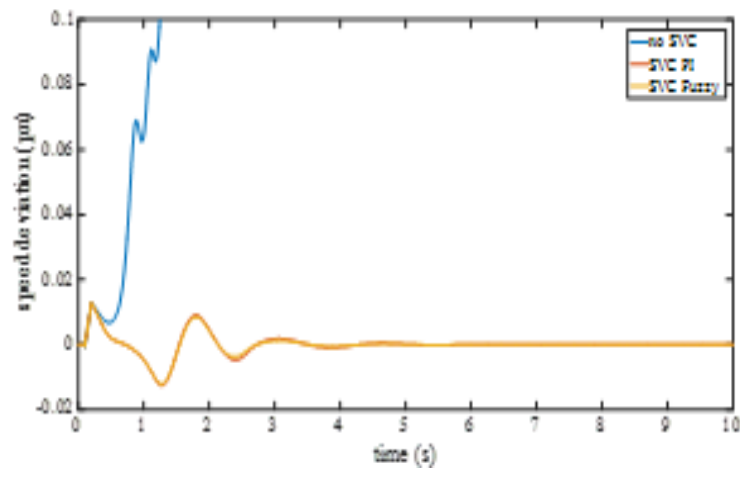

Figure 8. Speed deviation (p.u)

\section{CONCLUSION}

This paper proposes the simulation result of the fuzzy-based SVC stabilizer to improve the stability of the two-area power system. Normally, SVC's contribution to damping system oscillations resulting from voltage regulation alone is very poor. Adding SVC stabilizer can greatly improve oscillation damping and provides robustness despite its simple control rules. To the practical power systems, the control rules are quite simple to implement. However, PSS can provide effective damping to power systems that are very poor for a two-area system. Anyway the good damping and shorter setting time can be achieved by applying FPSVC together with PSS. 


\section{ACKNOWLEDGEMENTS}

The authors are grateful for the support granted by by Center for Robotics and Industrial Automation, Universiti Teknikal Malaysia Melaka (UTeM) in conducting this research and Ministry of Higher Education.

\section{REFERENCES}

[1] P. Kundur. "Power system stability and control," McGraw Hill, New York, 1994.

[2] T. Athay, R. Podmore and S.Virmani. "A Robust Control Strategy for Shunt and Series Reactive Compensators to Damp Electromechanical Oscillations," IEEE Transactions on Power Delivery, vol. 16, no. 4, pp. 812-817, Oct 2001.

[3] M.A.Abido. "Analysis and Assessment of STATCOM Based Damping Stabilizers for Power System Stability Enhancement". Electric Power System Research, vol. 73, pp. 177-185, 2005.

[4] N. Sabai, H. N. Maung, and T. Win. "Voltage Control and Dynamic Performance of Power Transmission System Using Static Var Compensator," World Academy of Science, Engineering and Technology, vol. 42, pp. 425-429, 2008.

[5] C. Rehtanz, Justin-J. Zhang, "New types of FACTS-devices for power system security and efficiency," IEEE, 2007 293-298.

[6] A.-A. Edris. "Series Compensation Schemes Reducing the Potential of Subsynchrounous Resonance," IEEE Transactions on Power Systems, vol. 5, no. 1, 1990.

[7] E. H. Zhou. "Application of Static Var Compensator to Increase Power System Damping," IEEE Transactions on Power Systems, vol. 8, no. 2, May 1993.

[8] M. E. Aboul.Ela, A. A. Sallam, J. D. Mc Calley. "Damping Controller Design for Power System Oscillation Using Global Signals," IEEE Transactions on Power Systems, vol. 11, no. 2, pp. 767-773, 1996.

[9] Y. Chang, Z. Xu. "A Novel SVC Supplementary Controllers Based on Wide Area Signals,” Electric Power Systems Research, vol. 77, pp. 1569-1574, 2007.

[10] Q. Gu, A. Pandey and S. K. Starrett. "Fuzzy Logic Control Schemes for Static VAR Compensator to Control System Damping Using Global Signalm,” Electric Power Systems Research, vol. 67, pp. 115-122, 2003.

[11] M. Andersen and T. B. Alvsten. "Static Var Compensator Models for Power Flow and Dynamic Performance Simulation," IEEE Industrial Applications Magazine, vol. 14, pp. 57-62, 2014.

[12] Y. S. Kim, G.Yoo and J. song. "A Practical Application Consideration for Power System Stabilizer (PSS) Control," IEEE Trans. on Power System, vol. 18, no. 1, pp. 305-312, 2013.

[13] R. L. Hauth, S. A. Miske, Jr. F. Nozari. "The Role and Benefits of Static VAR Systems in High Voltage Power System Applications," IEEE Transactions on Power Apparatus and Systems, pp. 3761-3770, 1982.

[14] I. Azim and H. Rahman, "Power System Stability Enhancement by Enhancing the Performance of SVC," Int. J. Sci. Eng. Technol. Res.,vol. 2,no. 3, pp. 579-584, 2013.

[15] P. K. S. Roy, G. K. M. Hasanuzzaman, Md. Moniruzzaman. "Improvement of Power System Stability by using SVC with Cascade PID Controller," Global Journal of Researches in Engineering Electrical and Electronics Engineering, vol. 13, no. 16, pp. 66-73, 2013.

[16] H. Watanabe, T. Shimizu and G. Kimura. "Allocation of FACTS Devices in Hydrothermal System," vol. 9, no. 3, pp. 72-78, 2014.

[17] S. H. Hosseini, A. Ajami. "Voltage Regulation and Transient Stability Enhancement of a Radial AC Transmission System using UPFC," IEEE Annual Conference Industrial Electronics Society, vol. 2, pp. 1150-1154, 2011.

[18] C. Vatankhah and A. Ebadi. "Simulation of Unified Static Var Compensator Power System Stabilizer for Arresting Subsynvhoronous Resonance," Res. J. Recent Sci, vol. 2, no. 1, pp. 21-24, 2013.

[19] O. K. Ovir and A. J. Ekpunobi. "Effect of Unified Power Flow Controllers on Transient Stability," Res. J. Recent Sci., vol. 2, no.1, pp. 25-31, 2013.

[20] Z. Sallameh and D. Taylor. "Variable Structure FACTS Controller for Power System Transient Stability," IEEE Trans. on Power Electronics, vol. 1, no. 9, pp. 36-40, 2012.

[21] W. Teulings, J. C. Marpinard, A. capel and D. O. Sullivan. “A New Maximum Power Point Tracking System," IEEE Trans. on Power Delivery, vol. 10, no. 2, pp. 1085-1097, 1995.

[22] V. E. Wagner. "A Practical Example of the Use of Static Compensator to Reduce Voltage Fluctuations," IEEE Trans. on Power Systems, vol. 11, no. 4, pp. 1937-1943, 1996 and Technology (Special Issue for ICETTAS '15), vol. 3, no. 4, pp. 363-367, 2015.

[23] N. H. Abbas, R. AL-MulaHumadi. "Power System Stability Enhancement using SVC with Modified PSO Tuned PID Controller," International Journal of Computer Applications vol. 71, no. 3, pp. 15-22, 2013.

[24] Habibur, Dr. Fayzur, Harun. "Power System Stability Improvement By Using SVC With TID Tuned PID Controller," International Journal of Advanced Research in Computer Engineering \&Technology (IJARCET), vol. 1, no. 8, pp. 93-98, 2012.

[25] H. Rahman, Dr. Md. Fayzur, Harun. "Stability Improvement of Power System By Using SVC With PID Controller," International Journal of Emerging Technology and Advanced Engineering, vol. 2, no. 7, pp. 226-233, 2012.

[26] H. Rahman, I. Pathan, Harun. "Power System Stability Improvement By Using SVC With Power System Controller," International Journal of Advanced Research in Computer Engineering \& Technology (IJARCET), vol. 1, no. 9, pp. $37-42,2012$

[27] Zalina Kamis, Mohd Ruddin Ab.Ghani, Muhammad Nizam Kamarudin, Hairol Nizam Mohd Shah, Jano Zanariah. "A Review on SVC control for power system stability with and without auxiliary controller," Bulletin of Electrical Engineering and Informatics, vol. 8, no. 3, pp. 761-768, 2019. 